\title{
Interleukin-6 requires JAK to stimulate inner cell mass expansion in bovine embryos
}

\author{
Lydia K Wooldridge1, Sally E Johnson¹, Rebecca R Cockrum² and Alan D Ealy ${ }^{1,2}$ \\ ${ }^{1}$ Department of Animal and Poultry Sciences, Virginia Polytechnic Institute and State University, Blacksburg, \\ Virginia, USA and ${ }^{2}$ Department of Dairy Science, Virginia Polytechnic Institute and State University, Blacksburg, \\ Virginia, USA
}

Correspondence should be addressed to A D Ealy; Email: ealy@vt.edu

\begin{abstract}
Supplementing interleukin-6 (IL6) to in vitro-produced bovine embryos increases inner cell mass (ICM) cell numbers in blastocysts. A series of studies were completed to further dissect this effect. Treatment with IL6 increased ICM cell numbers in early, regular and expanded blastocysts but had no effect on morulae total cell number. Treatment with IL6 for 30 min induced signal transducer and activator of transcription 3 (STAT3) phosphorylation and nuclear translocation in all blastomeres in early morulae and specifically within the ICM in blastocysts. Also, IL6 supplementation increased SOCS3 mRNA abundance, a STAT3-responsive gene, in blastocysts. Chemical inhibition of Janus kinase (JAK) activity from day 5 to day 8 prevented STAT3 activation and the IL6-induced ICM cell number increase. Global transcriptome analysis of blastocysts found that transcripts for IL6 and its receptor subunits (IL6R and IL6ST) were the most abundantly expressed IL6 family ligand and receptors. These results indicate that IL6 increases ICM cell numbers as the ICM lineage emerges at the early blastocyst stage through a STAT3-dependent mechanism. Also, IL6 appears to be the primary IL6 cytokine family member utilized by bovine blastocysts to control ICM cell numbers.

Reproduction (2019) 158 303-312
\end{abstract}

\section{Introduction}

The mammalian blastocyst inner cell mass (ICM) contains the ability to form every cell type within the adult body. It is of no surprise, then, that defects of the ICM can result in lethality (Feldman et al. 1995, Takeda et al. 1997, Arman et al. 1998). Understanding the development and needs of the ICM is crucial for embryos grown in vitro. Preimplantation embryos of several species, including humans, mice, rabbits and cattle, have been cultured in vitro to the blastocyst stage for decades (Tervit et al. 1972, Biggers 2012). However, in vitro culture systems lack the complexity of the oviductal environment, and this can hinder ICM development. This is particularly true for the bovine preimplantation embryo, which, when cultured in vitro, produces a smaller ICM during culture and after uterine transfer (Iwasaki et al. 1990, Bertolini et al. 2002, Fischer-Brown et al. 2004, Block et al. 2007, Loureiro et al. 2011). One way we may be able to improve in vitro-produced (IVP) bovine embryo competency is by supplementing IVP embryos with growth factors and cytokines produced by the oviduct and uterus. These bioactive factors are often referred to as embryokines, and their supplementation can improve IVP blastocyst development and pregnancy retention after embryo transfer (Loureiro et al. 2009, Tríbulo et al. 2017, Vailes et al. 2019). We recently discovered that interleukin-6 (IL6) increases the number of cells in the ICM of bovine blastocysts on day 8 of IVP development (Wooldridge \& Ealy 2019).

IL6 is perhaps the most well-known member of the IL6 cytokine family. Other members of this family include cardiotrophin-1 (CTF1 or CF1), cardiotrophinlike cytokine factor 1 (CLCF1), leukemia inhibitor factor (LIF), oncostatin M (OSM), ciliary neurotrophic factor (CNTF), and interleukins 11, 27 and 31 (IL11, IL27, IL31). All IL6 cytokine family members act through a receptor complex comprising a ligand-specific receptor subunit that permits high-affinity ligand binding (e.g. IL6R for IL6) and a common subunit (IL6ST, also known as gp130) that contains signal transducing regions (Scheller et al. 2011, Ataie-Kachoie et al. 2014). All family members utilize the IL6ST subunit to control several signal transduction pathways, the most prominent of which is the Janus kinase (JAK) and signal transducer and activator of transcription 3 (STAT3) system. The JAK/STAT3 pathway is essential for the ICM lineage in mice and cattle, but the specific ligands that regulate JAK/STAT3 activity in bovine embryos is unclear (Takeda et al. 1997, Meng et al. 2015). Several indications exist that members of the IL6 cytokine family serve in this capacity. Some family members serve as mouse embryonic stem cell pluripotency factors (Shmitt et al. 1991, Conover et al. 
1993, Nichols et al. 1994). Also, IL6 supplementation stimulates STAT3 phosphorylation and increases ICM cell numbers in porcine blastocysts (Shen et al. 2012).

The following work was completed to answer several questions about IL6's effects on bovine preimplantation embryos. First, we investigated the developmental stage at which IL6 first increases embryo cell number. We also used this information to determine if IL6 increases ICM cell number by skewing lineage specification toward ICM cells or by increasing expansion of the ICM lineage. Second, we investigated IL6's ability to activate the JAK/STAT3 pathway and the necessity of this pathway for IL6's effects. Finally, we utilized RNA sequencing to dissect the outcomes of IL6 treatment on blastocyst transcripts and to profile IL6 family member transcript abundance. Most of the studies began at day 5 of embryonic development because embryonic genome activation had occurred by this stage of development (8- to 16-cell stage), and thus, embryos could respond to external signals (Graf et al. 2014), and because these embryos were preparing to undergo compaction and embyronic lineage specification.

\section{Materials and methods}

No animals were used for this work. All studies were completed on slaughterhouse-derived materials. Unless specified otherwise, reagents were purchased from ThermoFisher Chemical Company.

\section{In vitro embryo production}

Bovine embryos were produced by in vitro maturation, fertilization and culture procedures described previously (Zhang et al. 2010, Wooldridge \& Ealy 2019). In brief, cumulusoocyte complexes (COCs) were collected by slashing follicles and placed in groups of 20-35 in 500 $\mu \mathrm{L} \mathrm{TCM-199} \mathrm{containing}$ Earle's salts and supplemented with $10 \%[\mathrm{v} / \mathrm{v}]$ fetal bovine serum (FBS; Atlanta Biologicals, Flowery Branch, Georgia, USA), $25 \mu \mathrm{g} / \mathrm{mL}$ bovine follicle-stimulating hormone (Bioniche Animal Health Canada Inc., Belleville, Ontario, Canada), 2 нg/ $\mathrm{mL}$ estradiol (Sigma-Aldrich), $22 \mu \mathrm{g} / \mathrm{mL}$ sodium pyruvate, $1 \mathrm{mM}$ L-alanyl-L-glutamine (Glutamax) and $25 \mu \mathrm{g} / \mathrm{mL}$ gentamicin sulfate. The COCs were matured for $21-24 \mathrm{~h}$ at $38.5^{\circ} \mathrm{C}$ in $5 \%$ $\mathrm{CO}_{2}$ in humidified air. The COCs were washed in HEPES-SOF and placed in groups of 150-200 in $3 \mathrm{~mL}$ SOF-FERT covered in paraffin oil (Ovoil; Vitrolife, Göteborg, Sweden) (Sakatani et al. 2012, Denicol et al. 2014). Frozen semen from four Holstein bulls (donation from Select Sires, Plain City, OH, USA) was thawed, and spermatozoa were isolated through a biphasic $(40 \%$ and $80 \%,[\mathrm{v} / \mathrm{v}])$ Bovipure ${ }^{\mathrm{TM}}$ density gradient (Nidacon; Spectrum Technologies, Healdsburg, CA, USA) before addition to the fertilization media at a concentration of 1 million sperm $/ \mathrm{mL}$ fertilization media. After incubation for $14-18 \mathrm{~h}$ at $38.5^{\circ} \mathrm{C}$ in $5 \% \mathrm{CO}_{2}$ in humidified air, presumptive zygote-cumulus complexes were denuded by gentle pipetting. Denuded presumptive zygotes were then washed in
HEPES-SOF and placed in groups of approximately 20-30 in droplets of $50 \mu \mathrm{L}$ of SOF-BE1 covered by paraffin oil and incubated at $38.5^{\circ} \mathrm{C}$ in $5 \% \mathrm{CO}_{2}, 5 \% \mathrm{O}_{2}$ and $90 \% \mathrm{~N}_{2}$ in humidified air (Fields et al. 2011).

\section{IL6 supplementation study}

A concentrated IL6 (recombinant bovine; Kingfisher Biotech, St. Paul, MN, USA) stock $(10 \mu \mathrm{g} / \mathrm{mL})$ was prepared in SOF containing $1 \%[\mathrm{w} / \mathrm{v}]$ bovine serum albumin (BSA) and stored in aliquots at $-80^{\circ} \mathrm{C}$. Stocks were only thawed once and were used immediately after thawing.

Either 0 or $100 \mathrm{ng} / \mathrm{mL}$ IL6 was provided on day 1 post fertilization ( $n=23-29$ embryos/drop; $2-7$ drops/ treatment, 6 replicates; total 578-657 embryos/treatment). On day 7 , embryos were separated by stage and fixed for immunofluorescent differential cell counting utilizing caudal type homeobox 2 (CDX2), a TE-specific transcription factor (see below for antibody specifications and procedures) ( $\mathrm{Wu}$ et al. 2016). Stages included morulae (compacted blastomere mass but no signs of a blastocoel cavity; $n=15-23$ /treatment), early blastocysts (blastocoel cavity $<50 \%$ of interior space; $n=7-17 /$ treatment), regular blastocysts (blastocoel $\geq 50 \%$ of interior space, not expanded; $n=37-43 /$ treatment) and expanded blastocysts (increase in diameter with or without zona pellucida hatching; $n=27-31$ /treatment).

\section{Assessment of STAT3 activity and its necessity for ICM development}

Day 5 embryos were transferred to drops of SOF-BE1 containing $5 \mu \mathrm{M}$ AZD1480 (JAK1/2 inhibitor; Selleckchem, Houston, TX, USA) or carrier only $(0.005 \%[\mathrm{v} / \mathrm{v}] \mathrm{DMSO})$ for $4 \mathrm{~h}$ and then were treated with 0 or $100 \mathrm{ng} / \mathrm{ml}$ IL6 for $30 \mathrm{~min}$ before fixation in $4 \%[\mathrm{w} / \mathrm{v}]$ paraformaldehyde. This JAK1/2 inhibitor was chosen based on a previous observation of its ability to block STAT3 activation in bovine embryos (Meng et al. 2015). Embryos ( $n=3-5$ embryos/replicate; 3 replicates; total 10-12 embryos/treatment) were processed for immunofluorescence analysis of STAT3 phosphorylation (pSTAT3 ${ }^{\text {Y705) }}$ and nuclear localization (see below for antibody specifications and procedures). Another experiment utilized blastocysts harvested on day 8 post fertilization ( $n=3-5$ blastocysts/ replicate; 2 replicates; total $7-8$ blastocysts/treatment) and incubated with 0 or $100 \mathrm{ng} / \mathrm{mL}$ IL6 for 30 min before fixation and pSTAT3 ${ }^{\mathrm{Y705}}$ analysis.

In a follow-up experiment, embryos harvested on day 5 post fertilization were placed into drops of SOF-BE1 ( $n=10$ embryos/drop; 10-30 embryos/treatment/replicate; 6 replicates; total 90-130 day 5 embryos/treatment) containing either 0 or $5 \mu \mathrm{M}$ AZD1480. After $4 \mathrm{~h}$, each drop of embryos received an injection of $1 \mu \mathrm{L}$ SOF-BE1 containing concentrated IL6 or carrier, to produce a final in-drop concentration of 0 or $100 \mathrm{ng} / \mathrm{mL}$ IL6. Blastocyst development was assessed on day 7 and 8 post fertilization. On day 8 , representative blastocysts ( $n=6-17$ blastocysts/treatment over 4 replicates) were collected, fixed and processed for cell counting. In one replicate of this study, the presence of SOX2, an ICM marker, 
was examined to confirm that the non-CDX2-stained cells (CDX2- cells) that reside within the inner clump of cells in blastocysts were indeed ICM cells.

\section{qRT-PCR}

On day 7, embryos were treated with $100 \mathrm{ng} / \mathrm{mL}$ IL6 or carrier only and incubated for $6 \mathrm{~h}$ at $38.5^{\circ} \mathrm{C}$ in $5 \% \mathrm{CO}_{2}, 5 \% \mathrm{O}_{2}$ and $90 \% \mathrm{~N}_{2}$ in humidified air. After $6 \mathrm{~h}$, pools of blastocysts ( $n=11-19 /$ treatment/replicate; 3 replicates) were collected, zona pellucidae were removed by brief exposure to Acidic Tyrode's Solution (Sigma-Aldrich), washed four times in sterile Dulbecco's phosphate-buffered saline (DPBS) containing $0.2 \%[\mathrm{w} / \mathrm{v}]$ polyvinylpyrrolidone (PBS-PVP), collected into $<10 \mu \mathrm{L}$ PBS-PVP in microcentrifuge tubes, snap frozen in liquid nitrogen, and stored at $-80^{\circ} \mathrm{C}$.

Total RNA was extracted by using the Qiagen RNeasy Micro Kit (Qiagen). The entire RNA sample was incubated with RNase-free DNAse I (Applied Biosystems, Inc.) and reverse transcribed using the High Capacity cDNA Reverse Transcription Kit (Applied Biosystems, Inc.). Negative controls did not receive reverse transcriptase. SybrGreen PCR Master Mix (Applied Biosystems, Inc.) was mixed with reverse transcription product and $250 \mathrm{nM}$ forward and reverse primers. After activation/denaturation $\left(95^{\circ} \mathrm{C}\right.$ for $\left.10 \mathrm{~min}\right)$, a twostep amplification sequence was set for 50 cycles $\left(95^{\circ} \mathrm{C}\right.$ for $15 \mathrm{~s}, 57^{\circ} \mathrm{C}$ for $\left.1 \mathrm{~min}\right)$. Each sample and primer combination were run in triplicate. Each primer pair (see Table 1 for primer list) was identified using the Primer-BLAST Program from the National Center for Biotechnology Information (U.S. National Library of Medicine, Bethesda, MD, USA) and synthesized by Integrated DNA Technologies (IDT; San Diego, CA, USA). Primer efficiency standard curve analysis was completed to verify adequate primer efficiency ( $\geq 90 \%$ efficiency). Dissociation curve analysis $\left(60-95^{\circ} \mathrm{C}\right)$ was completed after each PCR amplification to confirm the presence of one amplicon. SDHA was used as a housekeeping gene based on previously verified stability across early embryonic stages (Goossens et al. 2005). The $2^{[-d d C t]}$ approach was used to generate mRNA abundances relative to the non-IL6-treated embryos, depending on the study.

\section{RNA sequencing}

Day 5 embryos ( $n=25-31$ embryos/drop; 5-6 drops/treatment; 3 replicates), were treated with $100 \mathrm{ng} / \mathrm{mL}$ IL6 or carrier only via the addition of $2 \mu \mathrm{L}$ of treatment concentrated SOF-BEI to their existing culture drop. On day 8 , blastocysts $(n=10$ / treatment/replicate) were collected from each treatment group and their zona pellucidae were removed by brief exposure to Acidic Tyrode's Solution. Blastocysts were then washed four times in sterile PBS-PVP, collected into $<10 \mu \mathrm{L}$ PBS$P V P$ in microcentrifuge tubes, snap frozen in liquid nitrogen, and stored at $-80^{\circ} \mathrm{C}$. Total RNA was extracted by using the PicoPure RNA Isolation Kit (Applied Biosystems, Inc.). Genomic DNA was removed on-column by using the RNasefree DNAse 50 kit (Qiagen). Samples were shipped in dryice to Cofactor Genomics (St. Louis, MO, USA) for picoRNA library construction and sequencing using an Illumina-based platform with single end 75 base reads. Remaining blastocysts in each replicate were fixed for cell counting to confirm IL6 batch bioactivity ( $n=17-24$ blastocysts/treatment).

Sequence analysis was performed using CLC Genomics Workbench 11.0.1 (Qiagen). Reads were imported and adapters and low-quality reads were removed. The sequences were then aligned to the Bos taurus reference genome (Ensembl; UMB3.1). Expression values were expressed as reads per kilobase of transcript per million (RPKM). Differential gene expression was determined by empirical analysis using the Robinson and Smyth Exact Test (Robinson \& Smyth 2007). False discovery rate (FDR) was controlled at a rate of $5 \%$ using the Benjamini-Hochberg method (Benjamini \& Hochberg 1995). The Panther Classification system (version 14.0) was used to classify genes based on gene families, molecular function, biological processes and interacting pathways. Heat maps were generated through GraphPad Prism (version 8.0.2).

\section{Immunofluorescence}

Embryos were removed from culture and washed twice in PBSPVP. For SOX2 immunostaining, zona pellucidae were removed by brief exposure to Acidic Tyrode's Solution. Regardless of the target, embryos were fixed in $4 \%[\mathrm{w} / \mathrm{v}]$ paraformaldehyde for $15-20 \mathrm{~min}$ at room temperature and washed three times in PBS-PVP. For CDX2 and SOX2 studies, embryos were permeabilized using $0.25 \%$ [v/v] Triton-X for $20 \mathrm{~min}$ and then washed twice in wash buffer (DPBS containing $0.1 \%[\mathrm{w} / \mathrm{v}]$ BSA and $0.1 \%[\mathrm{v} / \mathrm{v}]$ Tween 20 ) before blocking for $1 \mathrm{~h}$ at room temperature in $10 \%$ horse serum. For pSTAT3 ${ }^{\mathrm{Y} 705}$ studies, embryos were permeabilized with $70 \%$ [v/v] ethanol for $5 \mathrm{~min}$ and washed once in blocking buffer $(10 \%[\mathrm{v} / \mathrm{v}]$ horse serum with $0.1 \%[\mathrm{v} / \mathrm{v}]$ Triton-X100) followed by two washes in wash buffer. Blocking for this antibody was completed with $10 \%$ $[\mathrm{v} / \mathrm{v}]$ horse serum containing $0.1 \%$ [v/v] Triton-X. All embryos were incubated overnight at $4{ }^{\circ} \mathrm{C}$ in primary antibodies for CDX2 (Biogenex, San Ramon, CA; AM392-5M, sold ready-touse), pSTAT3 ${ }^{\mathrm{Y705}}$ (Cell Signaling Technologies; 9145T; 1:100) or SOX2 (R\&D Systems; AF2018-SP; 1:300). Embryos were then washed three times and incubated at room temperature for $1 \mathrm{~h}$ with donkey anti-mouse FITC, 488 or 647 (for CDX2), donkey anti-rabbit 555 (for pSTAT3 ${ }^{\text {Y705 }}$ ), or donkey antigoat 647 (for SOX2). Embryos were washed three times and

Table 1 Primers used for quantitative RT-PCR.

\begin{tabular}{lllr}
\hline Gene & Reference or Genbank accession no. & Primer sequence $\left(5{ }^{\prime}-3\right)$ & Product size (bp) \\
\hline SOCS3 & NM_174466.2 & Forward: CGAGAAGATCCCTCTGGTGT & 77 \\
SDHA & Goossens et al. 2005 & Reverse: CGGTCTTCCGACAGAGATGT & 185 \\
& & Forward: GCAGAACCTGATGCTTTGTG & \\
\hline
\end{tabular}


incubated for $5 \mathrm{~min}$ at room temperature with DAPI $(1 \mu \mathrm{g} / \mathrm{mL})$. After washing once in PBS-PVP, the embryos were placed in 10\% [v/v] ProLong ${ }^{\mathrm{TM}}$ Gold Antifade diluted with PBS-PVP and either imaged by flattening on a glass slide or not flattening (for z-series acquisition), depending on the study. Immunoreactive complexes and DNA staining were visualized by using an Eclipse Ti-E inverted microscope equipped with an X-Cite 120 epifluorescence illumination system. Images were captured with DS-L3 digital camera and assembled with NIS-Elements Software (Nikon Instruments). Cell counting was completed by using the cell counter plugin in the program FIJI (ImageJ) to label and record individual nuclei stained for CDX2 $\left(\mathrm{CDX} 2^{+}\right.$, indicating TE) or DAPI only (CDX2-/DAPI ${ }^{+}$, indicating ICM) (Schindelin et al. 2012).

\section{Statistical analysis}

All analyses were completed by least-squares ANOVA using the general linear model of the Statistical Analysis System (Proc GLM; SAS for Windows, version 9.4; SAS Institute Inc.). Individual comparisons were partitioned further, when necessary, by using the probability of difference (PDIFF) test of SAS. Relative mRNA abundance data were log-transformed before analysis, but data are presented as fold change with standard error. For each embryo development study, the replicate was used as the experimental unit. This replicate refers to the mean developmental percentages observed on each in vitro embryo production occasion (i.e. each IVP run). Percentage data (e.g. blastocyst formation rates) were arcsine-transformed before analysis but are presented as nontransformed means and S.E.M. The Tukey honestly significant difference test was used for all blastocyst formation data. Blastomere numbers and differential staining analysis used individual embryos as the experimental unit. Statistical significance was determined at $P \leq 0.05$.

\section{Results}

\section{IL6 increases ICM and total cell numbers in day 7 blastocysts but not morulae}

Previous work determined that IL6 supplementation beginning at day 5 post fertilization increases ICM cell numbers at day 8 post fertilization (Wooldridge \& Ealy 2019). A follow-up study examined whether beginning IL6 treatment on day 1 post fertilization affected ICM and TE cell numbers in embryos harvested on day 7 post fertilization (Fig. 1). No effect of IL6 was detected on the incidence of morulae and early and expanded blastocyst formation on day 7 (data not shown). However, IL6 treatment tended $(P=0.06)$ to reduce regular $(7.5 \pm 2 \mathrm{vs}$ $13.1 \pm 2 \%$ for controls) and total blastocyst formation (15.4 \pm 3 vs $20.4 \pm 4 \%$ for controls). Treatment with IL6 did not affect total cell number in morulae (Fig. 1A). Supplementation with IL6 increased $(P<0.05)$ ICM cell numbers in early, regular and expanded blastocysts (Fig. $1 \mathrm{~B}, \mathrm{D}$ and $\mathrm{F})$. Treatment also increased $(P<0.05)$ total cell numbers in regular and expanded blastocysts but not early blastocysts. Numbers of TE cells were reduced
$(P<0.05)$ by IL6 treatment in early blastocysts but were unchanged in regular and expanded blastocysts. The ICM:TE ratio was increased $(P<0.05)$ by IL6 at each stage of blastocyst development (Fig. 1C, E and G). Example images of immunostained embryos within each stage are presented in Fig. 2.

\section{IL6 activates the JAK/STAT3 pathway in bovine embryos}

The mode of IL6 action on embryonic cells was examined by determining whether IL6 stimulates STAT3 phosphorylation and nuclear localization. On day 5 post fertilization, control embryos showed no nuclear pSTAT3 $^{\text {Y705 }}$ staining, but embryos treated with IL6 for
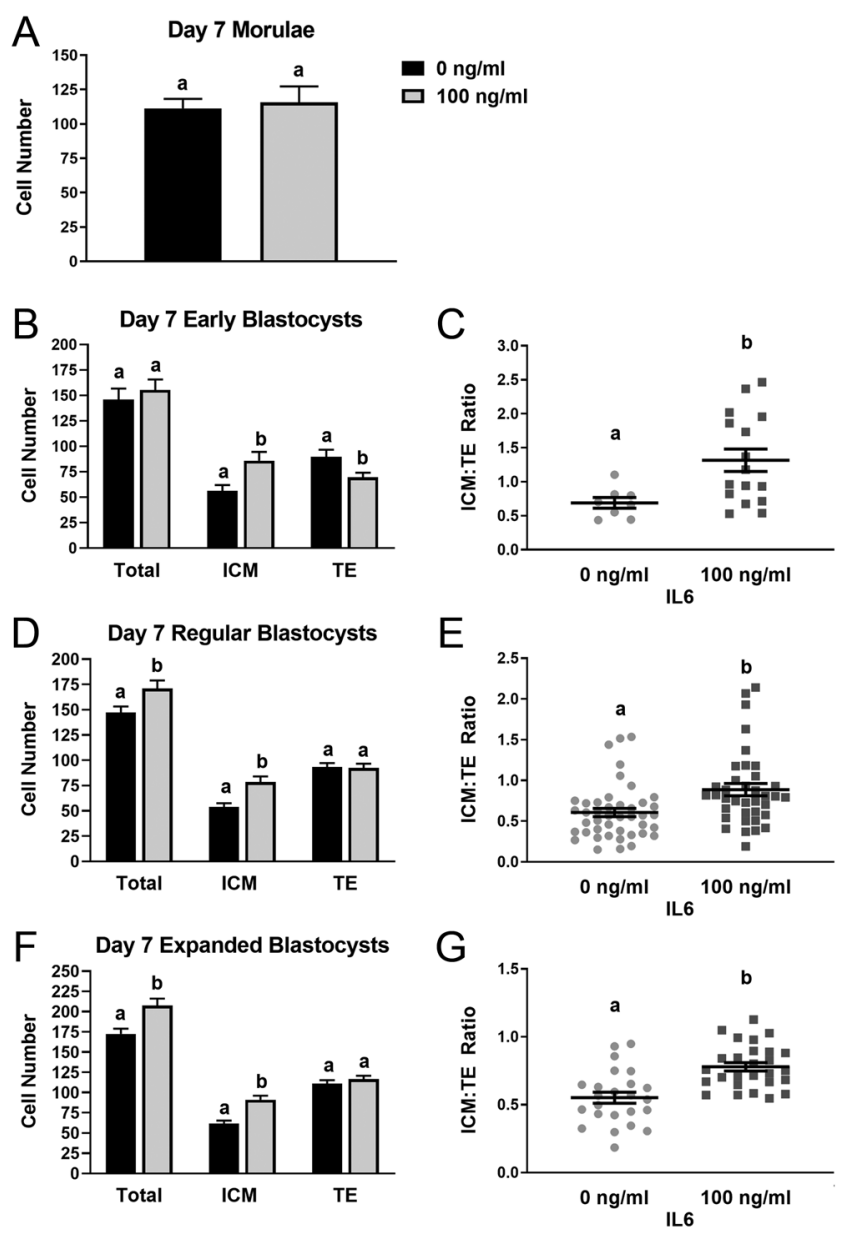

Figure 1 Supplementation with IL6 stimulates ICM cell numbers in bovine blastocysts evaluated on day 7 post fertilization. Embryos received either $100 \mathrm{ng} / \mathrm{mL}$ IL6 or carrier only $(0 \mathrm{ng} / \mathrm{mL})$. Morula and blastocysts were separated by stage on day 7 , fixed and immunostained. Panel A: Average total cell counts for morulae. Panels B, D, F: Total cell numbers and numbers of ICM and TE cells in early (B), regular (D) and expanded (F) blastocysts. Panels C, E, G: The ICM:TE ratios for individual day 7 embryos categorized as early (C), regular (E) and expanded (G) blastocysts. Corresponding means and S.E.M.S are indicated by the bars. Different superscripts within each panel indicate differences $(P<0.05)$. 


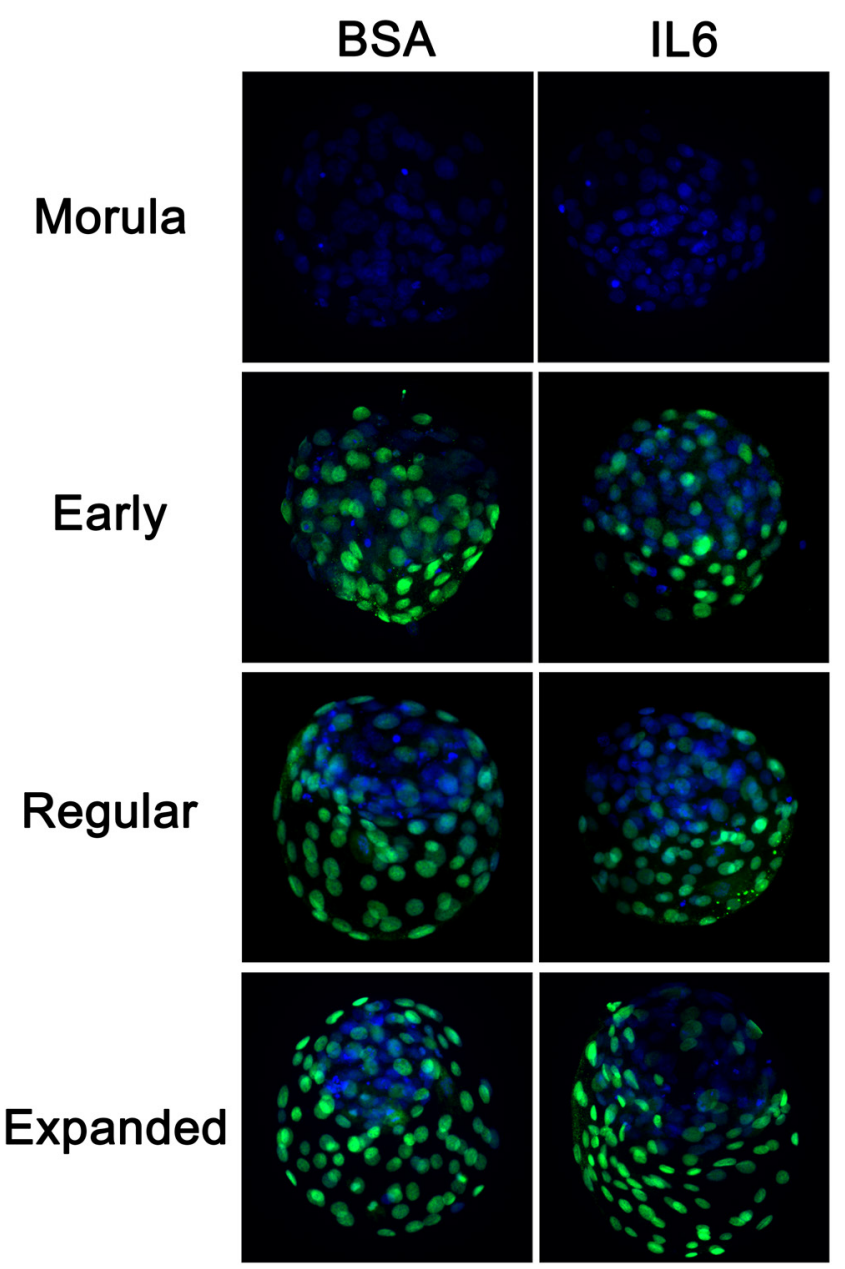

Figure 2 Representative day 7 embryos treated with 0 or $100 \mathrm{ng} / \mathrm{ml}$ IL6 from day 1 to 7 post fertilization. On day 7, embryos were harvested, grouped based on stage of development and treatment, fixed and immunostained. DAPI staining was used at the morula stage to determine total cell numbers. Differential cell staining was completed at the blastocyst stages. Nuclei representing TE are indicated by $\mathrm{CDX} 2^{+} / \mathrm{DAPI}^{+}$staining (green) and the ICM nuclei are $\mathrm{CDX}^{-} / \mathrm{DAPI}^{+}$(blue)

30 min contained nuclear-localized staining in most cells (Fig. 3A). When the study was completed on day 8 of development, control blastocysts showed slight nuclear pSTAT3 ${ }^{\mathrm{Y} 705}$ staining in all ICM cells and no staining in the TE (Fig. 3B). Exposure to IL6 for $30 \mathrm{~min}$ intensified nuclear pSTAT3 ${ }^{\mathrm{Y} 705}$ staining specifically in the ICM (Fig. 3B).

A second study examined the ability of IL6 to stimulate STAT3 activity by examining SOCS3 expression, a STAT3-inducible signal silencer (Starr et al. 1997). This study began at day 7 to capture blastocyst responses to IL6 treatment. Exposure of day 7 embryos to $100 \mathrm{ng} /$ $\mathrm{mL}$ IL6 for $6 \mathrm{~h}$ increased SOCS3 transcript abundance (Fig. 3C).

The next series of studies examined the consequences of blocking IL6-induced STAT3 activation beginning

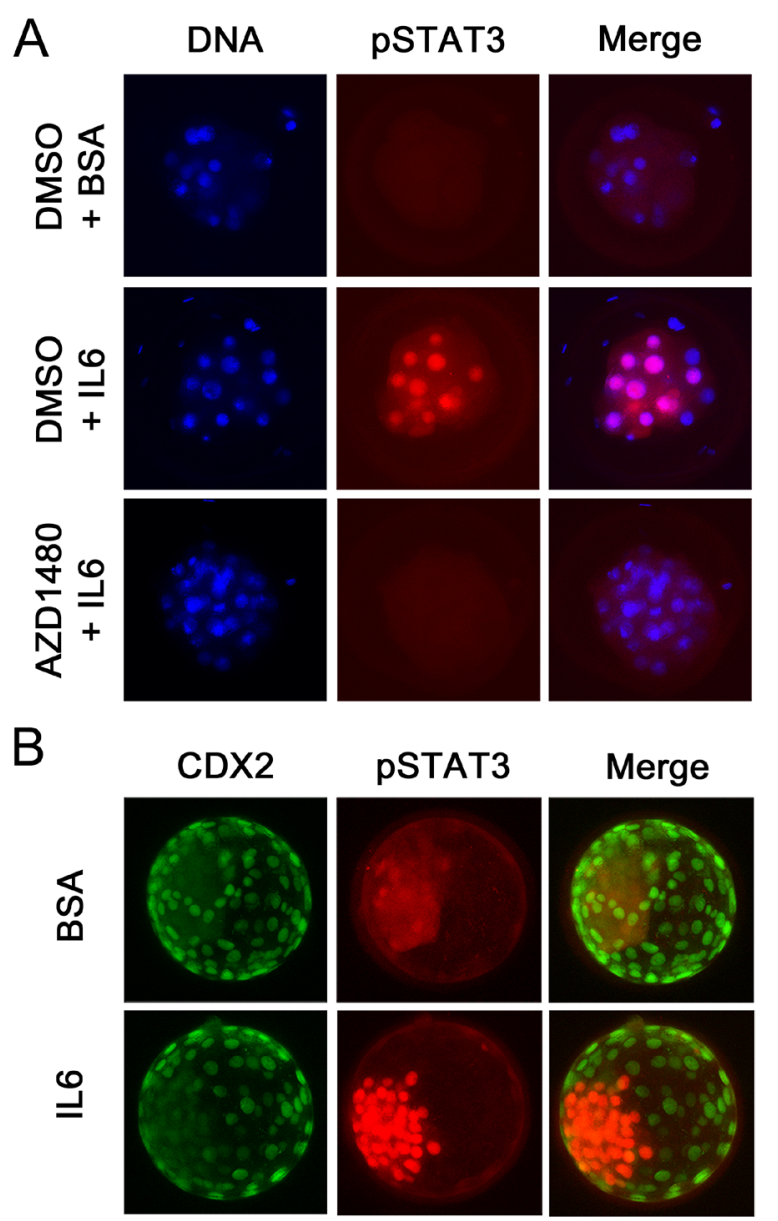

C STAT3 Inducible SOCS3 Expression

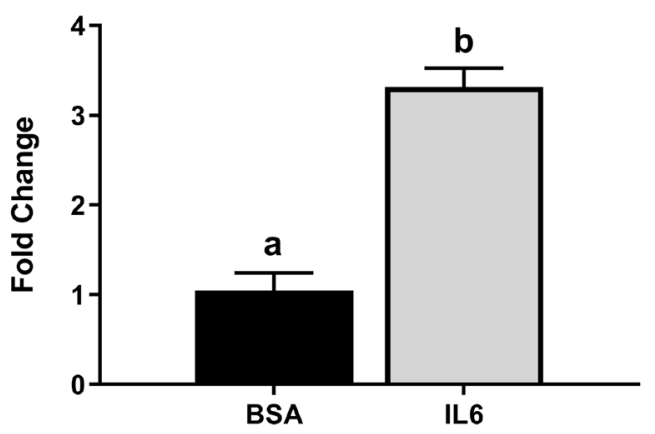

Figure 3 IL6-dependent stimulation of STAT3 phospho-activation and nuclear localization in day 5 and 8 embryos. Panel A: A representative sampling of embryos ( $>8$ cells) that were pre-treated with 0 (DMSO only) or $5 \mu \mathrm{M}$ AZD1480 for $4 \mathrm{~h}$ before treatment with 0 (BSA only) or $100 \mathrm{ng} / \mathrm{mL}$ IL6 for $30 \mathrm{~min}$. Embryos were immunostained to detect pSTAT3 ${ }^{+}$(red) and counterstained with DAPI (blue) to detect all nuclei. Panel B: A representative sampling of day 8 blastocysts treated with 0 or $100 \mathrm{ng} / \mathrm{mL}$ IL 6 for $30 \mathrm{~min}$ before immunostaining to detect $\mathrm{PSTAT}^{+}$nuclei (red) and $\mathrm{CDX}^{+}$(TE marker, green). All images were obtained by z-series acquisition and subsequent focusing of the image via an Extended Depth of Field module (Nikon). Panel C: Influence of $100 \mathrm{ng} / \mathrm{mL}$ IL6 on SOCS3 expression after $6 \mathrm{~h}$ of treatment in day 7 blastocysts. Different superscripts within each panel indicate differences $(P<0.05)$. 


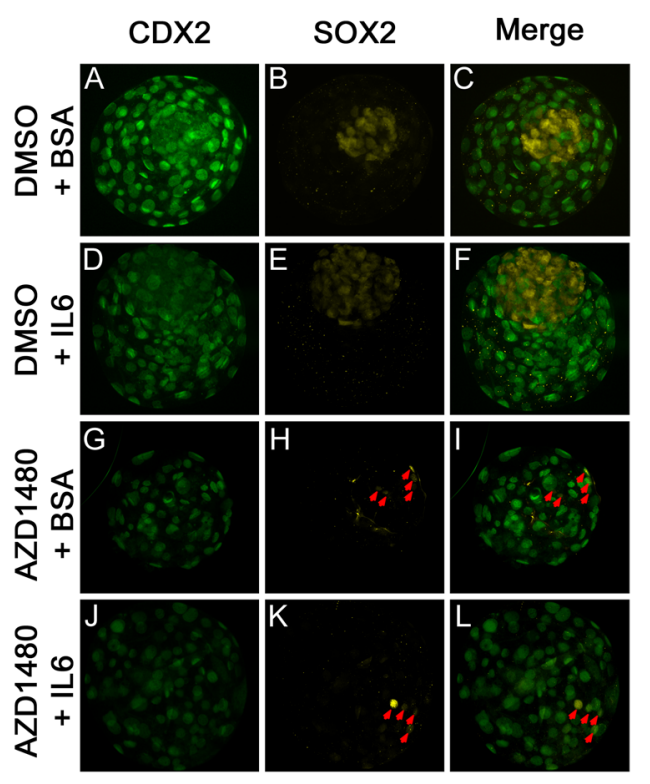

at day 5 post fertilization. Pre-treatment with $5 \mu \mathrm{M}$ AZD1480, a pharmacological inhibitor of JAK1/2, effectively blocked IL6-induced pSTAT3 ${ }^{\text {Y705 }}$ staining and nuclear localization on day 5 post fertilization (Fig. $3 \mathrm{~A})$. Examples of cell staining in day 8 blastocyst with or without AZD1480 exposure is provided in Fig. 4 (panels A-L). Supplementation with IL6 beginning on day 5 did not affect total blastocyst or expanded blastocysts development on day 7 or 8 (Fig. 4M). Treatment with AZD1480 alone reduced $(P<0.05)$ the percentage of total blastocysts on day 7 and 8 and reduced $(P<0.05)$ the percentage of expanded blastocysts on day 8 (Fig. 4M). Co-supplementation of AZD1480 and IL6 partially restored blastocyst development on days 7 and 8 (Fig. 4M).

As expected, ICM cell numbers were increased $(P<0.05)$ after IL6 exposure beginning on day 5, but ICM cell numbers were reduced $(P<0.05)$ following exposure to AZD1480 beginning on day 5, regardless of whether IL6 treatment was administered (Fig. 4N). Neither AZD1480 treatment, nor IL6 supplementation nor the combination of treatments affected TE cell numbers. Total blastomere numbers were reduced with AZD1480 treatment in both IL6-treated and non-treated embryos $(P<0.05$; data not shown).

To confirm that the DAPI ${ }^{+} / \mathrm{CDX}^{-}$nuclei in AZD1480treated blastocysts were ICM cells, a subset of embryos was stained for SOX2, a pluripotency marker commonly used to mark the ICM (Fig. 4B, E, H and K) (Goissis \& Cibelli 2014). Numerous $S O X 2^{+}$nuclear staining was detected in the BSA controls and IL6-treated groups (Fig. $4 \mathrm{~B}$ and $\mathrm{E}$ ). However, only a few SOX2+ nuclei were detected in embryos exposed to AZD1480 (Fig. 4H and K). Curiously, this JAK inhibition resulted in some cells dual-staining for CDX2 and SOX2 (indicated by arrows in Fig. $4 \mathrm{H}$, I and $\mathrm{K}, \mathrm{L}$ ).

\section{IL6 has minimal effects on the bovine embryo transcriptome}

Blastocysts produced from embryos treated with IL6 or carrier only from day 5 to day 8 were harvested, pooled and processed for RNA sequencing. Blastocysts not used for the RNA analysis were processed for cell counting. Treatment with IL6 increased $(P<0.05)$ ICM (74.71 \pm 5.5 vs $47.2 \pm 6.6$ cells in controls), TE $(131.8 \pm 8.2$ vs $105.3 \pm 8.7$ cells in controls) and total cell numbers $(206.5 \pm 12.3$ vs $152.5 \pm 14.4$ cells in controls). Treatment with IL6 also increased $(P<0.05)$ the ICM:TE ratio $(0.6 \pm 0.05$ vs $0.4 \pm 0.04$ in controls).

The analysis contained an average of $47,021,778$ reads/sample and identified 22,104 transcripts and 19,981 genes (Supplementary file 1, see section on supplementary data given at the end of this article). Treatment with IL6 affected the expression of 91 genes $(\geq 1.5$-fold; $\geq 1.0$ RPKM; FDR $<0.05$ ), with 60 upregulated and 31 downregulated (Supplementary file 1). Panther analysis identified genes associated with signaling molecules (PC00207; FAM43B, A2M, FZD10, GDF15), receptors (PC00197; GPR68, NPSR1, SORL1, LAMA1, FZD10), and transcription factors (PC00218: IRF1, BHLHE40, ZNF423). Panther Pathway Analysis identified genes involved with chemokine and cytokine signaling (P00031; VWF, ITGA2, NFKB) and integrin signaling (P00034; LAMA1, ITGA2, CAV1). Panther-GO Slim Analysis for molecular function identified several genes associated with protein binding (GO:0005515; EXOC3L4, FZD10, KIFC1, CSTB, TRIB3, SERPINA3, IGFBP4, TMEM88, SEPT4, CAV1, GDF15, FAM43B, A2M, CIITA, BHLHE4O).

The dataset was used to describe the abundance of IL6 family member ligands and receptors in bovine blastocysts (Fig. 5A). For IL6 family receptors, IL6R, IL6ST and IL11RA expression was detected (RPKM >1.0). 

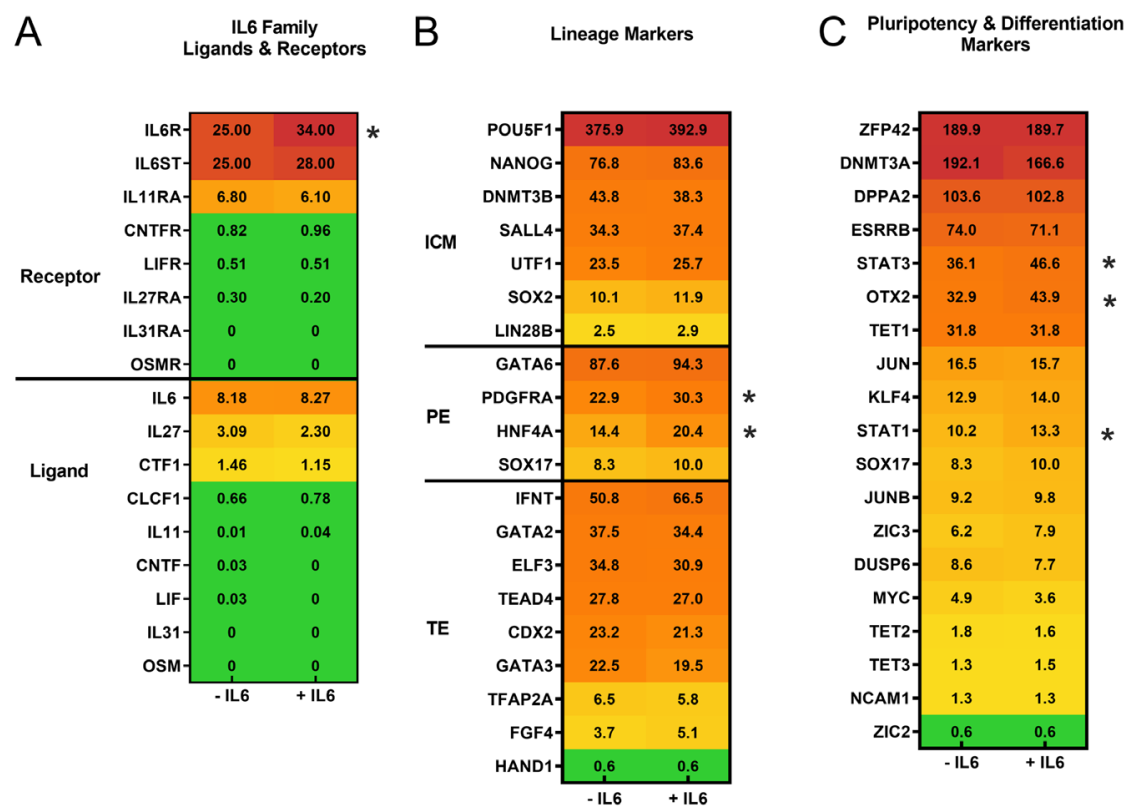

Figure 5 Expression analysis of IL6 family ligand and receptors, markers of embryonic lineages, and markers of pluripotency and differentiation after IL6 exposure.

Supplementation with 0 or $100 \mathrm{ng} / \mathrm{mL}$ IL6 was completed from day 5 to 8 post fertilization. Blastocysts recovered on day 8 were processed for RNA extraction and RNA sequencing was completed using an Illumina-based platform and the CLC Genomics Workbench 11.0.1 to align sequences to the Bos taurus reference genome (Ensembl;UMB3.1). Panel A:

Abundances of IL6 family member ligands and receptors with and without IL6

supplementation. Panel B: Transcript abundance for genes associated with ICM, PE and TE lineages. Panel C: Transcript abundance of pluripotency and differentiation markers identified in the dataset. Expression values in each rectangle are expressed as reads per kilobase of transcript per million (RPKM). Asterisks indicate transcripts with differential expression based on IL6 treatment (FDR <0.05).
CNTFR, LIFR and IL27RA were present in low abundance (RPKM 0.2-1.0) and other receptors were not detected (RPKM <0.2). Treatment with IL6 increased (FDR <0.05) IL6R abundance but not the other receptors. The most abundant IL6 family ligand was IL6. Both IL27 and CTF1 were also detected at moderate abundance (RPKM >1.0) and CLCF1 was detected at low abundance (RPKM 0.2$1)$. Other ligands were not detected (RPKM $<0.2)$.

The expression profiling dataset also was used to examine the expression of genes associated with ICM, TE and primitive endoderm (PE) lineages and with pluripotency and differentiation (Fig. 5B and C) (Bogliotti et al. 2018). No changes in gene expression were detected in ICM and TE lineage markers, but two $P E$ lineage markers were expressed in greater amounts (FDR <0.05) after IL6 treatment (PDGFRA, HNF4A) (Fig. 5B). Also, only 3 of the 19 genes identified in the dataset associated with pluripotency and differentiation were increased (FDR <0.05) after IL6 treatment (STAT1, STAT3, OTX2) (Fig. 5C).

\section{Discussion}

Interleukin-6 is best known as a pro-inflammatory cytokine that regulates the acute phase response and other inflammatory responses (Scheller et al. 2011, Ho et al. 2015). This group recently described that IL6 also serves as an embryotrophic factor in cattle, and it contains the unique ability to stimulate ICM cell numbers in bovine blastocysts (Wooldridge \& Ealy 2019). This work built upon previous findings and described the apparent signaling mechanism responsible for this IL6 action.

The ontogeny of IL6's effect on ICM cell numbers was assessed by examining changes in ICM cell numbers as blastocysts began forming on day 7 post fertilization.
We were unable to discriminate between future ICM and TE cells at the morula stage with CDX2 differential staining. However, no changes in blastomere numbers were detected at the morula stage after IL6 treatment. Therefore, it seems probable that IL6's proliferative or anti-apoptotic actions are not occurring until the blastocyst begins to form. It is difficult to speculate whether IL6 promotes blastomere allocation to the ICM as the blastocyst is being formed or if IL6 promotes ICM cell lineage expansion after the ICM is formed. We found that early blastocysts on day 7 contain greater ICM cell numbers and fewer TE cell numbers after IL6 treatment, suggesting a lineage reallocation. However, regular and expanded blastocysts contained greater ICM but similar TE cell numbers, suggesting ICM cell proliferation after IL6 treatment. Moreover, there also may be proliferation in TE cells between the early and later stages of development.

In our previous work, we did not detect an effect of IL6 on TE cell numbers (Wooldridge \& Ealy 2019). However, in this work, we detected two occasions when TE cell numbers changed after IL6 treatment. The first was in early blastocysts and the second effect was found in the day 8 blastocysts used as controls for our RNA sequencing study. The reasons for these occurrences were not pursued, and it is not clear if this effect can be replicated or if it occurred on these occasions merely due to chance. The noteworthy effect of IL6 on ICM numbers was pursued instead of these minor changes in TE numbers that occurred in some but not all studies.

Previously, no known activator of STAT3 in bovine preimplantation embryos and blastocysts had been described. This work discovered that IL6 activates STAT3 in bovine embryos. Nuclear staining of STAT3 ${ }^{\text {Y705 }}$ was detected in IL6-treated embryos in nearly all blastomeres 
on day 5 and solely within the ICM on day 8 . Additionally, IL6 increased expression of SOCS3, a STAT3-responsive gene, in day 7 blastocysts after $6 \mathrm{~h}$ of treatment. Similar findings have been observed in other species. Blocking embryo-derived IL6 activity (by antibody-based neutralization) in mouse blastocysts reduced STAT3 phosphorylation and nuclear localization (Do et al. 2013). IL6 also stimulated STAT3 phosphorylation in pig blastocysts, although this activation could be detected both in the ICM and TE (Shen et al. 2012). The SOCS3 increase was not observed in our RNA sequencing data. This is not surprising given that embryos were exposed to IL6 for $72 \mathrm{~h}$ in the RNA sequencing study, and SOCS3 expression is known to spike initially but decrease after long-term IL6 treatment (Starr et al. 1997).

The inhibition of the JAK/STAT3 pathway prevented the IL6-induced expansion of ICM cell numbers in bovine blastocysts. Additionally, a few of the embryos exposed to the JAK1/2 inhibitor began degenerating approximately $24-48 \mathrm{~h}$ after blastocyst formation (2 of 36 JAK1/2-treated blastocysts versus none of the non-treated blastocysts). We also experienced some difficulty obtaining acceptable quality blastocysts for cell counting in JAK1/2-inhibited blastocysts (5 of 11 blastocysts were not used because of poor quality). These observations resemble the rapid, post-blastocyst degeneration observed in STAT3-null mouse embryos (Takeda et al. 1997, Do et al. 2013). Therefore, present findings point to IL6 acting through STAT3 to mediate ICM development in cattle, pigs and mice. However, we cannot confirm that the JAK/STAT3 is the only pathway IL6 employs to impact ICM development because inhibition of the JAK/STAT3 pathway always results in a loss of ICM cells, regardless of IL6 supplementation.

Most of the cell counting studies herein did not utilize an ICM-specific marker. We concluded that blastomeres lacking CDX2 represent ICM. In one study, we confirmed these $\mathrm{CDX} 2^{-}$cells were ICM cells by SOX2 immunostaining. Other studies did not utilize SOX2 for cell counting because it can be detected both in the nucleus and cytoplasm of the bovine ICM, and this complicates cell counting (Goissis \& Cibelli 2014). Curiously, the JAK1/2-inhibited blastocysts contained a subset of $\mathrm{SOX}^{+}$and $\mathrm{CDX}^{+}$dual-positive nuclei (arrows in Fig. 4H, I and $\mathrm{K}, \mathrm{L}$ ). The reason for this phenomenon was not explored. This could suggest a possible disruption of lineage specification or it may simply reflect an artifact of cell immunostaining.

It is interesting that IL6 supplementation may partially alleviate the negative effect of JAK1/2 inhibition on blastocyst formation. Inhibition of JAK $1 / 2$ reduced blastocyst formation on day 7 and 8 , but blastocyst rates were partially restored with IL6 and AZD1480 co-supplementation. This suggests that IL6 may act on embryos through non-STAT3-dependent systems to control blastocoel formation and/or TE development. However, IL6 supplementation did not affect blastocyst formation in a group culture setting in this and previous work, but this group recently showed that supplementing IL6 during a high-stress situation (individual embryo culture), facilitated blastocyst formation (Wooldridge \& Ealy 2019). This may indicate that IL6's ability to promote blastocyst development in bovine embryos is observed primarily during sub-optimal culture conditions.

The RNA profiling work provided minimal insights into the mechanisms that mediate IL6's effects on the ICM. Time-response studies and studies that specifically examine the ICM likely are needed to decipher gene expression changes associated with IL6 treatment. However, this dataset was useful for describing IL6 as a major controller of bovine embryogenesis within the IL6 family. IL6R was the most abundantly expressed ligand-specific receptor. Moreover, IL6 supplementation increased IL6R expression. Likewise, IL6 was the most abundantly expressed ligand. The sequencing also suggests that many of the other IL6 family members are unlikely to affect embryonic STAT3 expression in bovine blastocysts. Either the ligand-specific receptor is absent or endometrial and/or embryonic ligand expression is lacking during the time of blastocyst development. One family member of note was IL11. Blastocyst expression of ILI1RA is interesting because IL11 is a putative uterine-produced embryokine. It exhibits a temporal expression pattern in bovine endometrium, with greatest abundance on day 7 post estrus (Oliveira et al. 2013).

The RNA sequencing dataset also provided evidence that IL6 supplementation had minimal effects on embryo lineage formation and early pluripotency and differentiation potential. IL6 supplementation did not alter the expression of lineage markers associated with ICM and TE development, but alterations in PE lineage markers were detected. The PE will produce the yolk sac, and the yolk sac of IVP bovine embryos is poorly vascularized in comparison to embryos produced in vivo (Alberto et al. 2013, Mess et al. 2017). We detected an increase in PDGFRA2 and HNF4A transcripts with IL6 treatment, both of which are vasculogenesis and angiogenesis factors associated with the PE. Therefore, these changes in gene expression may reflect downstream IL6 effects that may improve yolk sac development and function. Only 3 of the 19 pluripotency and differentiation markers found in the RNA sequencing dataset were increased by IL6 treatment (STAT1, STAT3, OTX2). Previous reports found that expression for each of these transcriptional regulators is controlled by IL6 family members in non-embryonic tissues, indicating that it not unexpected to detect these responses to IL6 treatment in bovine embryos (Brocke-Heidrich et al. 2004, Zhang et al. 2005). Future studies will be necessary to confirm if these differences in transcript abundance also yield protein and functional differences.

In summary, this work provides additional evidence that IL6 functions as an embryokine in bovine preimplantation embryos. IL6 activates STAT3 
phosphorylation and nuclear localization specifically within the ICM. Also, blocking the JAK/STAT3 pathway prevents the beneficial effects of IL6 on ICM development. However, due to the apparent necessity of STAT3 for ICM survival, we cannot completely confirm that IL6 acts solely through the JAK/STAT3 pathway to elicit its ICM effects. The physiological relevance of IL6 remains speculative. It is expressed in the oviduct, endometrium and embryo during early pregnancy in cattle and a recent report found that IL6 transcripts were among the most prominently expressed cytokines in the oviduct on day 3 and 5 and in the endometrium on day 5 (Starr et al. 1997, Shen et al. 2012, Wooldridge \& Ealy 2019). However, it remains unknown if IL6 is required for normal bovine embryo development or if it functions primarily as a facilitator of ICM development only during in vitro embryo production. Lastly, evidence provided herein suggests that IL6 is the predominant mediator of IVP embryo ICM development among IL6 family members. The implications of enhancing ICM development in IVP embryos has yet to be explored, but all current indications suggest that IL6 treatment could improve IVP embryo survival after transfer in cattle.

\section{Supplementary data}

This is linked to the online version of the paper at https://doi.org/10.1530/REP-19-0286.

\section{Declaration of interest}

The authors declare that there is no conflict of interest that could be perceived as prejudicing the impartiality of the research reported.

\section{Funding}

This project was supported by Agriculture and Food Research Initiative Competitive grant numbers 2017-67015-26461 and 2018-67030-28727 from the USDA National Institute of Food and Agriculture. Fellowship support for L K W was provided by the Institute for Critical Technology and Applied Science (ICTAS) Doctoral Scholars Program at Virginia Tech and by Agriculture and Food Research Initiative Competitive grant number 2018-67011-27993 from the USDA National Institute of Food and Agriculture.

\section{Author contribution statement}

A D E conceived of the studies, oversaw the completion of the studies and statistical analyses, and wrote the final version of the manuscript. S E J provided critical technical expertise on embryo immunostaining and assisted in writing the manuscript. L KW performed the experiments, analyzed the data and wrote the initial drafts of the manuscript. R R C provided critical technical expertise on RNA-sequencing analysis.

\section{Acknowledgments}

Authors thank Dr Matthew Utt, Dr Bo Harstine and Select Sires, Inc. (Plain City, OH) for donating the bovine semen used for this work. The authors also thank graduate and undergraduate students at Virginia Tech for assisting with bovine in vitro embryo production, and especially Dr Sarah McCoski, McCauley Vailes and Chelsea Abbott.

\section{References}

Alberto ML, Meirelles FV, Perecin F, Ambrósio CE, Favaron PO, Franciolli AL, Mess AM, dos Santos JM, Rici RE, Bertolini M et al. 2013 Development of bovine embryos derived from reproductive techniques. Reproduction, Fertility, and Development 25 907-917. (https://doi. org/10.1071/RD12092)

Arman E, Haffner-Krausz R, Chen Y, Heath JK \& Lonai P 1998 Targeted disruption of fibroblast growth factor (FGF) receptor 2 suggests a role for FGF signaling in pregastrulation mammalian development. PNAS 95 5082-5087. (https://doi.org/10.1073/pnas.95.9.5082)

Ataie-Kachoie P, Pourgholami MH, Richardson DR \& Morris DL 2014 Gene of the month: interleukin 6 (IL-6). Journal of Clinical Pathology 67 932-937. (https://doi.org/10.1136/jclinpath-2014-202493)

Benjamini Y \& Hochberg Y 1995 Controlling the false discovery rate: a practical and powerful approach to multiple testing. Journal of the Royal Statistical Society: Series B 57 289-300. (https://doi. org/10.1111/j.2517-6161.1995.tb02031.x)

Bertolini M, Beam SW, Shim H, Bertolini LR, Moyer AL, Famula TR \& Anderson GB 2002 Growth, development, and gene expression by in vivo- and in vitro-produced day 7 and 16 bovine embryos. Molecular Reproduction and Development 63 318-328. (https://doi.org/10.1002/ mrd.90015)

Biggers JD 2012 IVF and embryo transfer: historical origin and development. Reproductive Biomedicine Online 25 118-127. (https:// doi.org/10.1016/j.rbmo.2012.04.011)

Block J, Fischer-Brown AE, Rodina TM, Ealy AD \& Hansen PJ 2007 The effect of in vitro treatment of bovine embryos with IGF-1 on subsequent development in utero to day 14 of gestation. Theriogenology 68 153161. (https://doi.org/10.1016/j.theriogenology.2007.04.045)

Bogliotti YS, Wu J, Vilarino M, Okamura D, Soto DA, Zhong C, Sakurai M, Sampaio RV, Suzuki K, Belmonte JC et al. 2018 Efficient derivation of stable primed pluripotent embryonic stem cells from bovine blastocysts. PNAS 115 2090-2095. (https://doi.org/10.1073/pnas.1716161115)

Brocke-Heidrich K, Kretzschmar AK, Pfeifer G, Henze C, Löffler D, Koczan D, Thiesen HJ, Burger R, Gramatzki M \& Horn F 2004 Interleukin-6-dependent gene expression profiles in multiple myeloma INA-6 cells reveal a Bcl-2 family-independent survival pathway closely associated with Stat3 activation. Blood 103 242-251. (https://doi. org/10.1182/blood-2003-04-1048)

Conover JC, Ip NY, Poueymirou WT, Bates B, Goldfarb MP, DeChiara TM \& Yancopoulos GD 1993 Ciliary neurotrophic factor maintains the pluripotentiality of embryonic stem cells. Development 119 559-565.

Denicol AC, Block J, Kelley DE, Pohler KG, Dobbs KB, Mortensen CJ, Ortega MS \& Hansen PJ 2014 The WNT signaling antagonist Dickkopf-1 directs lineage commitment and promotes survival of the preimplantation embryo. FASEB Journal 28 3975-3986. (https://doi.org/10.1096/fj.14253112)

Do DV, Ueda J, Messerschmidt DM, Lorthongpanich C, Zhou Y, Feng B, Guo G, Lin PJ, Hossain MZ, Zhang W et al. 2013 A genetic and developmental pathway from STAT3 to the OCT4-NANOG circuit is essential for maintenance of ICM lineages in vivo. Genes and Development 27 1378-1390. (https://doi.org/10.1101/gad.221176.113)

Feldman B, Poueymirou W, Papaioannou VE, DeChiara TM \& Goldfarb M 1995 Requirement of FGF-4 for postimplantation mouse development. Science 267 246-249. (https://doi.org/10.1126/science.7809630)

Fields SD, Hansen PJ \& Ealy AD 2011 Fibroblast growth factor requirements for in vitro development of bovine embryos. Theriogenology $751466-$ 1475. (https://doi.org/10.1016/j.theriogenology.2010.12.007)

Fischer-Brown AE, Lindsey BR, Ireland FA, Northey DL, Monson RL, Clark SG, Wheeler MB, Kesler DJ, Lane SJ, Weigel KA et al. 2004 
Embryonic disc development and subsequent viability of cattle embryos following culture in two media under two oxygen concentrations. Reproduction, Fertility, and Development 16 787-793. (https://doi. org/10.1071/RD04026)

Goissis MD \& Cibelli JB 2014 Functional characterization of SOX2 in bovine preimplantation embryos. Biology of Reproduction 9030. (https://doi.org/10.1095/biolreprod.113.111526)

Goossens K, Poucke M, Soom A, Vandesompele J, Zeveren A \& Peelman LJ 2005 Selection of reference genes for quantitative real-time PCR in bovine preimplantation embryos. BMC Developmental Biology 5 1-9. (https://doi.org/10.1186/1471-213X-5-27)

Graf A, Krebs S, Heininen-Brown M, Zakhartchenko V, Blum H \& Wolf E 2014 Genome activation in bovine embryos: review of the literature and new insights from RNA sequencing experiments. Animal Reproduction Science 149 46-58. (https://doi.org/10.1016/j.anireprosci.2014.05.016)

Ho LJ, Luo SF \& Lai JH 2015 Biological effects of interleukin-6: clinical applications in autoimmune diseases and cancers. Biochemical Pharmacology 97 16-26. (https://doi.org/10.1016/j.bcp.2015.06.009)

Iwasaki S, Yoshiba N, Ushijima H, Watanabe S \& Nakahara T 1990 Morphology and proportion of inner cell mass of bovine blastocysts fertilized in vitro and in vivo. Journal of Reproduction and Fertility 90 279-284. (https://doi.org/10.1530/jrf.0.0900279)

Loureiro B, Bonilla L, Block J, Fear JM, Bonilla AQ \& Hansen PJ 2009 Colony-stimulating factor 2 (CSF-2) improves development and posttransfer survival of bovine embryos Producedin vitro. Endocrinology 150 5046-5054. (https://doi.org/10.1210/en.2009-0481)

Loureiro B, Block J, Favoreto MG, Carambula S, Pennington KA, Ealy AD \& Hansen PJ 2011 Consequences of conceptus exposure to colonystimulating factor 2 on survival, elongation, interferon- $\tau$ secretion, and gene expression. Reproduction 141 617-624. (https://doi.org/10.1530/ REP-10-0511)

Meng F, Forrester-Gauntlett B, Turner P, Henderson H \& Oback B 2015 Signal inhibition reveals JAK/STAT3 pathway as critical for bovine inner cell mass development. Biology of Reproduction 93 132. (https://doi. org/10.1095/biolreprod.115.134254)

Mess AM, Carreira ACO, Marinovic de Oliveira C, Fratini P, Favaron PO, Barreto RDSN, Pfarrer C, Meirelles FV \& Miglino MA 2017 Vascularization and VEGF expression altered in bovine yolk sacs from IVF and NT technologies. Theriogenology 87 290-297. (https://doi. org/10.1016/j.theriogenology.2016.09.012)

Nichols J, Chambers I \& Smith A 1994 Derivation of germline competent embryonic stem cells with a combination of interleukin- 6 and soluble interleukin-6 receptor. Experimental Cell Research 215 237-239. (https:// doi.org/10.1006/excr.1994.1338)

Oliveira LJ, Mansourri-Attia N, Fahey AG, Browne J, Forde N, Roche JF, Lonergan P \& Fair T 2013 Characterization of the Th profile of the bovine endometrium during the oestrous cycle and early pregnancy. PLOS ONE 8 1-13. (https://doi.org/10.1371/journal.pone.0075571)

Robinson MD \& Smyth GK 2007 Moderated statistical tests for assessing differences in tag abundance. Bioinformatics 23 2881-2887. (https://doi. org/10.1093/bioinformatics/btm453)

Sakatani M, Alvarez NV, Takahashi M \& Hansen PJ 2012 Consequences of physiological heat shock beginning at the zygote stage on embryonic development and expression of stress response genes in cattle. Journal of Dairy Science 95 3080-3091. (https://doi.org/10.3168/jds.2011-4986)

Scheller J, Chalaris A, Schmidt-Arras D \& Rose-John S 2011 The proand anti-inflammatory properties of the cytokine interleukin-6.
Biochimica et Biophysica Acta 1813 878-888. (https://doi.org/10.1016/j. bbamcr.2011.01.034)

Schindelin J, Arganda-Carreras I, Frise E, Kaynig V, Longair M, Pietzsch T, Preibisch S, Rueden C, Saalfeld S, Schmid B et al. 2012 Fiji: an opensource platform for biological-image analysis. Nature Methods 9 676682. (https://doi.org/10.1038/nmeth.2019)

Shen XH, Cui XS, Lee SH \& Kim NH 2012 Interleukin-6 enhances porcine parthenote development in vitro, through the IL-6/Stat3 signaling pathway. Journal of Reproduction and Development 58 453-460. (https://doi.org/10.1262/jrd.2012-015)

Shmitt RM, Bruyns E \& Snodgrass HR 1991 Hematopoietic development of embryonic stem cells in vitro: cytokine and receptor gene expression. Genes and Development 5 728-740. (https://doi.org/10.1101/ gad.5.5.728)

Starr R, Willson TA, Viney EM, Murray LJ, Rayner JR, Jenkins BJ, Gonda TJ, Alexander WS, Metcalf D, Nicola NA et al. 1997 A family of cytokineinducible inhibitors of signalling. Nature 387 917-921. (https://doi. org/10.1038/43206)

Takeda K, Noguchi K, Shi W, Tanaka T, Matsumoto M, Yoshida N, Kishimoto T \& Akira S 1997 Targeted disruption of the mouse Stat3 gene leads to early embryonic lethality. PNAS 94 3801-3804. (https://doi. org/10.1073/pnas.94.8.3801)

Tervit HR, Whittingham DG \& Rowson LE 1972 Successful culture in vitro of sheep and cattle ova. Journal of Reproduction and Fertility 30 493497. (https://doi.org/10.1530/jrf.0.0300493)

Tríbulo P, Bernal Ballesteros BH, Ruiz A, Tríbulo A, Tríbulo RJ, Tríbulo HE, Bo GA \& Hansen PJ 2017 Consequences of exposure of embryos produced in vitro in a serum-containing medium to dickkopf-related protein 1 and colony stimulating factor 2 on blastocyst yield, pregnancy rate, and birth weight. Journal of Animal Science 95 4407-4412. (https:// doi.org/10.2527/jas2017.1927)

Vailes MT, McCoski SR, Wooldridge LK, Reese ST, Pohler KG, Roper DA, Mercadante VR \& Ealy AD 2019 Post-transfer outcomes in cultured bovine embryos supplemented with epidermal growth factor, fibroblast growth factor 2, and insulin-like growth factor 1. Theriogenology 124 1-8. (https://doi.org/10.1016/j.theriogenology.2018.09.023)

Wooldridge LK \& Ealy AD 2019 Interleukin-6 increases inner cell mass numbers in bovine embryos. BMC Developmental Biology 19 2. (https:// doi.org/10.1186/s12861-019-0182-z)

Wu X, Song M, Yang X, Liu X, Liu K, Jiao C, Wang J, Bai C, Su G, Liu X et al. 2016 Establishment of bovine embryonic stem cells after knockdown of CDX2. Scientific Reports 6 28343. (https://doi.org/10.1038/srep28343)

Zhang SS, Liu MG, Kano A, Zhang C, Fu XY \& Barnstable CJ 2005 STAT3 activation in response to growth factors or cytokines participates in retina precursor proliferation. Experimental Eye Research 81 103-115. (https://doi.org/10.1016/j.exer.2005.01.016)

Zhang K, Hansen PJ \& Ealy AD 2010 Fibroblast growth factor 10 enhances bovine oocyte maturation and developmental competence in vitro. Reproduction 140 815-826. (https://doi.org/10.1530/REP-10-0190)

Received 28 June 2019

First decision 5 August 2019

Revised manuscript received 8 August 2019

Accepted 13 August 2019 